\title{
28 Research Square \\ Identification and validation of miRNA reference genes in poplar under pathogen stress
}

Lichun Zhang

Beijing Forestry University

Xiaoqian Yang

Beijing Forestry University

Yiyi Yin

Beijing Forestry University

Jinxing Wang

Jiangsu Academy of Agricultural Sciences

Yanwei Wang ( $\nabla$ ywwang@bjfu.edu.cn )

Beijing Forestry University https://orcid.org/0000-0002-4111-4843

\section{Research Article}

Keywords: Reference genes, miRNAs, Poplarl, qRT-PCR, Canker

Posted Date: February 25th, 2021

DOI: https://doi.org/10.21203/rs.3.rs-225734/v1

License: (a) This work is licensed under a Creative Commons Attribution 4.0 International License.

Read Full License 


\section{Abstract}

Quantitative real time polymerase chain reaction (qRT-PCR) is a common method to analyze gene expression. Due to differences in RNA quantity, quality, and reverse transcription efficiency between qRTPCR samples, reference genes are used as internal standards to normalize gene expression. However, few universal genes especially miRNAs have been identified as reference so far. Therefore, it is essential to identify reference genes that can be used across various experimental conditions, stress treatments, or tissues. In this study, 14 microRNAs (miRNAs) and 5.8S rRNA were assessed for expression stability in poplar trees infected with canker pathogen. Using three reference gene analysis programs, we found that miR156g and miR156a exhibited stable expression throughout the infection process. miR156g and miR156a were then tested as internal standards to measure the expression of miR1447 and miR171c, and the results were compared to small RNA sequencing (RNA-seq) data. We found that when miR156a was used as the reference gene, the expression of miR1447 and miR171c were consistent with the small RNA-seq expression profiles. Therefore, miR156a was the most stable miRNAs examined in this study, and could be used as a reference gene in poplar under canker pathogen stress, which should enable comprehensive comparisons of miRNAs expression and avoid the bias caused by different lenth between detected miRNAs and traditional referece genes. The present study has expanded the miRNA reference genes available for gene expression studies in trees under biotic stress.

\section{Full Text}

Due to technical limitations, full-text HTML conversion of this manuscript could not be completed. However, the latest manuscript can be downloaded and accessed as a PDF.

\section{Figures}




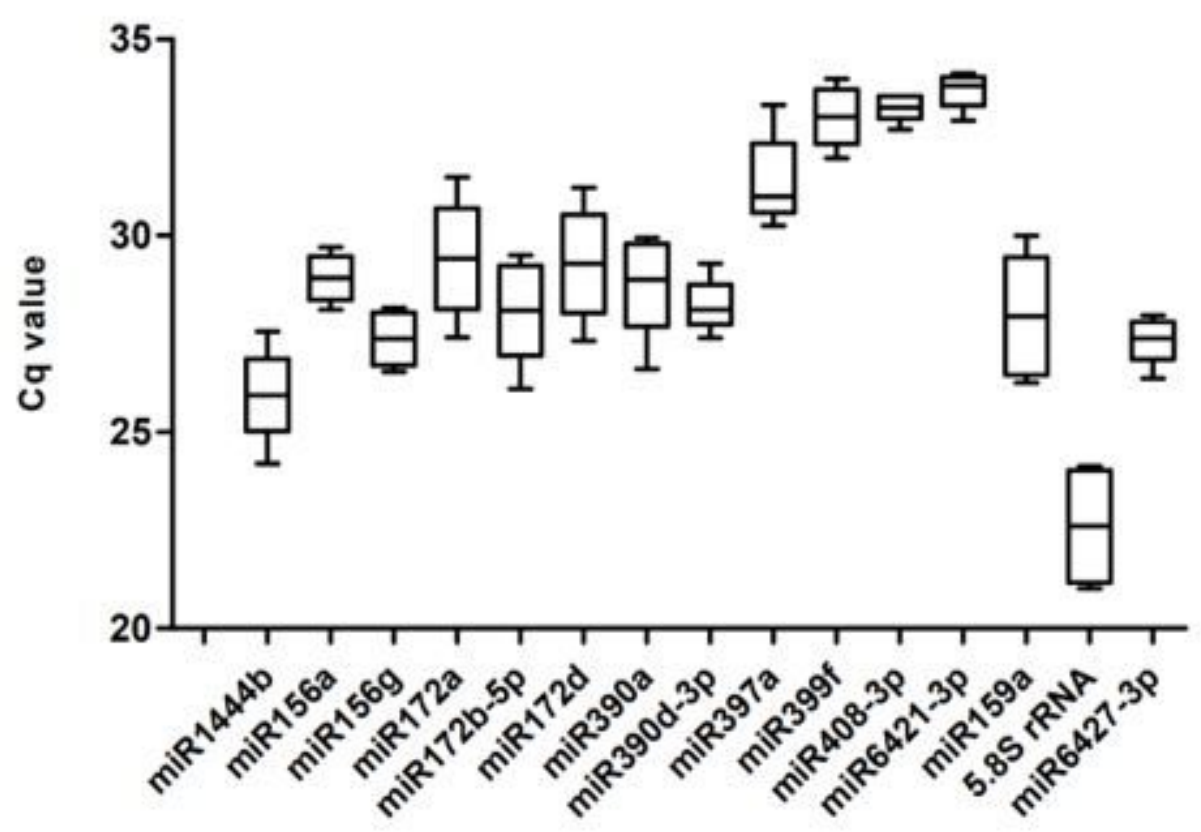

Figure 1

The expression levels of candidate reference genes. Box plots shows the $\mathrm{Cq}$ values of 15 candidate reference genes. The box indicates the 25th and 75th percentiles, and the whisker caps represent the maximum and minimum values. The cross in box denotes the median 
A

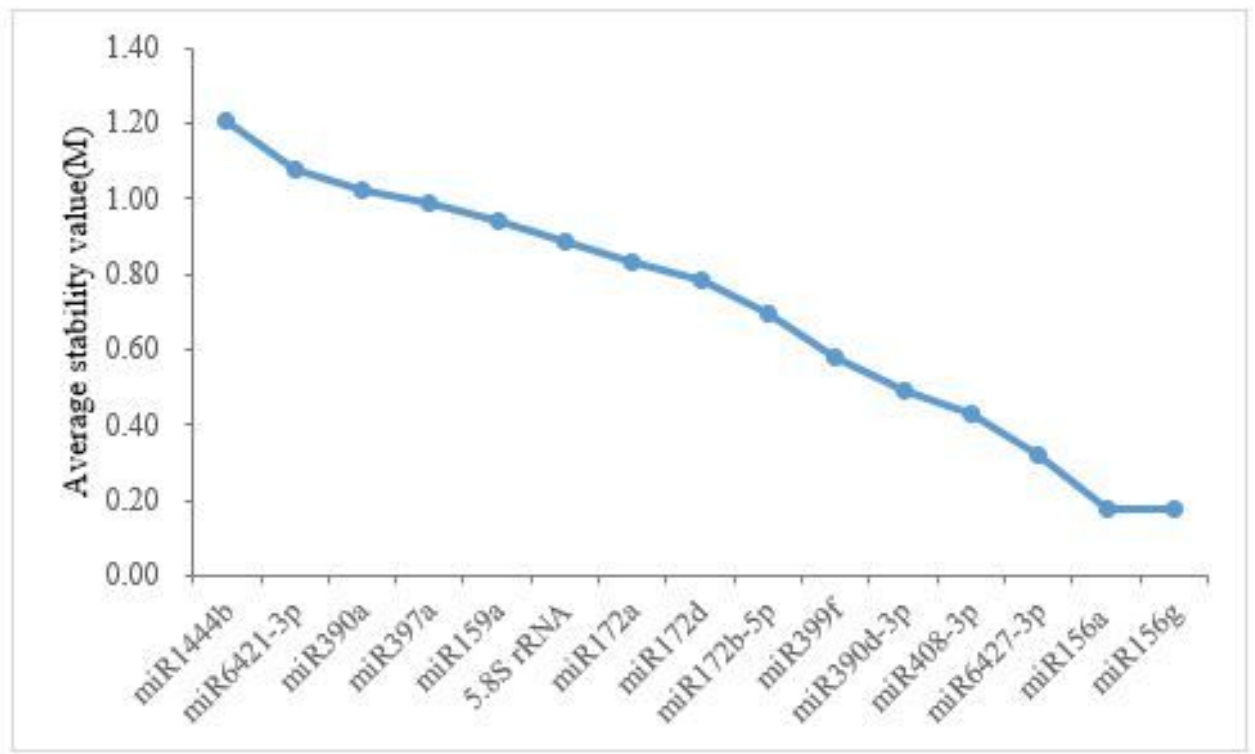

B

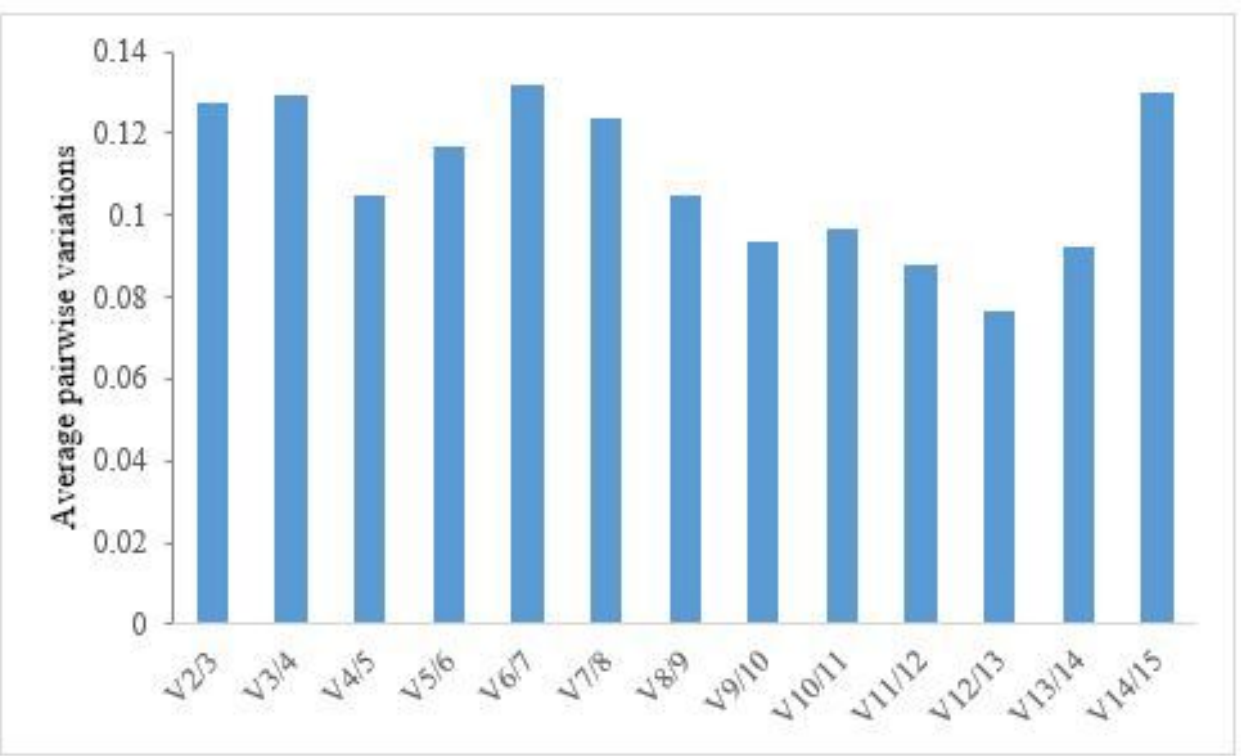

Figure 2

GeNorm assessment of candidate reference genes stability a $M$ values of the 15 candidate reference genes. A lower value of average expression stability indicates more stable expression $b$ Determination of the optimal number of reference genes for normalization. Pairwise variation $(V n / V n+1)$ analysis of 15 candidate reference genes in poplar treated with biotic stress. the value of $V n / V n+1$ selection threshold is 0.15 


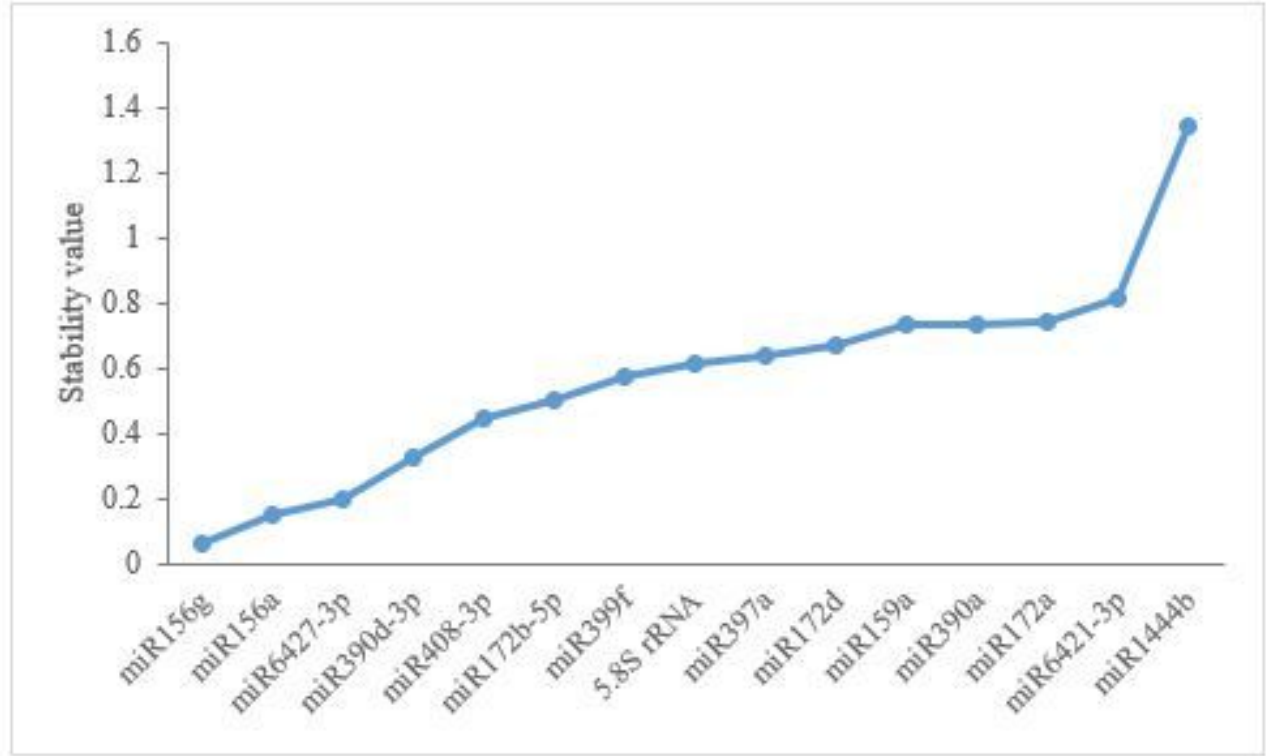

Figure 3

Ranking of 15 candidate reference genes in order of their expression stability calculated by NormFinder. Lower Stability value means the higher expression stability

A

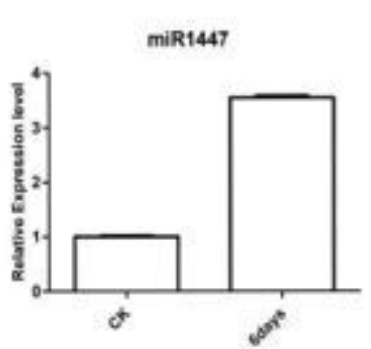

C

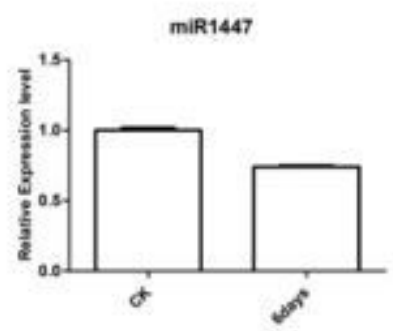

E

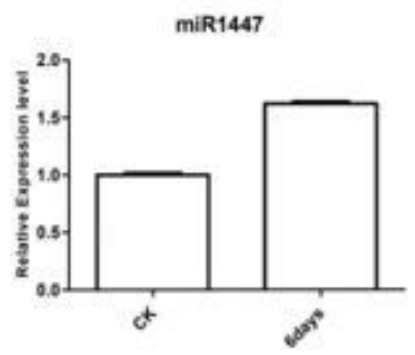

B

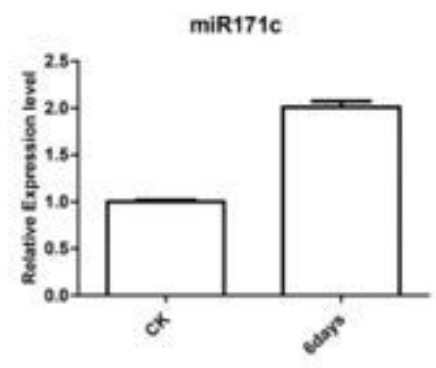

D

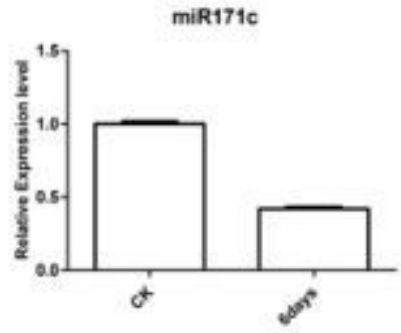

$\mathbf{F}$

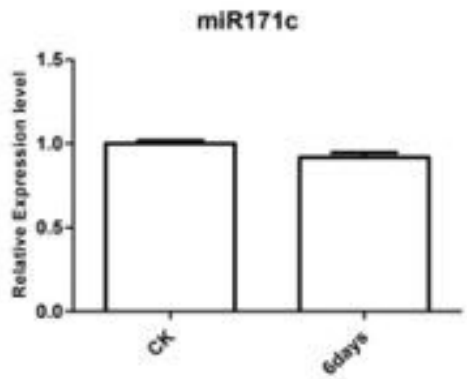

Figure 4 
The expression abundance of miR1447 and miR171c based on miR156g or as reference gene. miR156a as reference gene $(a, b)$. miR156g as reference gene $(c, d)$. miR156a together with miR156g as reference gene $(e, f)$

\section{Supplementary Files}

This is a list of supplementary files associated with this preprint. Click to download.

- SupplemenaryfigureS1.docx

- SupplemenaryfigureS2.docx

- SupplemenaryfigureS3.docx

- SupplementarytableS1.docx

- SupplementarytableS2.docx 